Article

\title{
Enhanced Stress Corrosion Cracking Resistance of Ultrafine-Grained Cu-Cr-Zr Alloy Fabricated via Equal-Channel Angular Pressing
}

\author{
Qingjuan Wang *, Dan Liu, Libo Tong *, Ying Zhou, Wei Wang ${ }^{\circledR}$, Haixiong Zhou and Ruixue Fan \\ School of Metallurgy Engineering, Xi'an University of Architecture and Technology, Xi'an 710055, China \\ * Correspondence: jiandawqj@163.com (Q.W.); lbtong@xauat.edu.cn (L.T.); Tel.: +86-1399-285-5295 (Q.W.)
}

Received: 15 May 2019; Accepted: 21 July 2019; Published: 25 July 2019

\begin{abstract}
The microstructure evolution and stress corrosion cracking (SCC) behaviors of ultrafine-grained (UFG) $\mathrm{Cu}-\mathrm{Cr}-\mathrm{Zr}$ alloys processed by equal-channel angular pressing (ECAP) and coarse-grain (CG) $\mathrm{Cu}-\mathrm{Cr}-\mathrm{Zr}$ alloys within $\mathrm{NaNO}_{2}$ solution were systematically investigated in the current study. After deformation by eight ECAP passes, the grain size was refined to $\sim 200 \mathrm{~nm}$. The slow strain rate tensile (SSRT) tests showed that the ultimate tensile strength (UTS) of CG samples in solution was slightly lower than that in the air, and the elongation was decreased from $57.3 \%$ to $52.6 \%$. In contrast, both the UTS and elongation of UFG samples in air and solution were almost identical. In $\mathrm{NaNO}_{2}$ solution, the CG fracture surface showed an obvious dissolution, microvoids, and minor cracks, while the surface of the UFG fracture was relatively smooth. The resistance of UFG samples to SCC could be significantly enhanced compared with CG samples. The grain boundary volume fraction of UFG alloy was dramatically increased, which reduced the formation of pitting corrosion. In addition, the uniform distribution of $\mathrm{Cr}$ particles also improved the corrosion resistance of UFG alloys.
\end{abstract}

Keywords: $\mathrm{Cu}-\mathrm{Cr}-\mathrm{Zr}$ alloys; stress corrosion cracking; ECAP; grain size

\section{Introduction}

$\mathrm{Cu}-\mathrm{Cr}-\mathrm{Zr}$ alloy is a typical precipitation-strengthened alloy with excellent mechanical properties, and is widely used in industrial fields involving high mechanical strength and high electrical conductivity, such as integrated circuit lead frames, continuous casting machine crystallizer lining, and the preparation of electric resistance welding electrodes [1-3]. Severe plastic deformation (SPD) is an effective method for improving the mechanical properties of materials and refining grains. Among them, ECAP (equal-channel angular pressing) is one of the most widely used technologies in SPD, and can produce an ultrafine-grained (UFG) structure in $\mathrm{Cu}-\mathrm{Cr}-\mathrm{Zr}$ alloy with superior mechanical properties [4,5]. Unfortunately, the serious corrosion failure problems of $\mathrm{Cu}$ alloys greatly limit their engineering applications [6,7]. $\mathrm{Cu}$ alloys are particularly susceptible to stress corrosion cracking (SCC) when subjected to the synergy of mechanical stress and corrosion medium. Recent studies have insufficiently focused on the SCC behaviors of UFG Cu alloys [8-10].

The corrosion behavior of UFG materials varies depending on the grain size, corrosive medium, and other factors [11,12]. $\mathrm{Cu}$ alloys are highly susceptible to SCC in $\mathrm{NaNO}_{2}$ solutions. Rebak et al. [13] showed that in $\mathrm{NaNO}_{2}$ solution with different $\mathrm{pH}$ values, the $\mathrm{Cu}$ alloy (brass) presented an obvious SCC behavior. Yamasaki et al. [14] reported that the resistance of the UFG Cu to SCC was higher than that of its coarse-grained (CG) counterpart in $1 \mathrm{M} \mathrm{NaNO}_{2}$ solution. 
Many previous reports on the improvement of the corrosion resistance for UFG $\mathrm{Cu}$ alloys are controversial. Wang et al. [15] studied the electrochemical properties of the nanocrystalline surfaces of a brass alloy produced by sandblasting and annealing, which proved that the nanocrystalline surface had higher resistance to corrosion. Sadawy et al. [16] reported that the bronze alloys subjected to ECAP exhibited higher corrosion resistance compared with the as-cast alloy. However, Vinogradov et al. [17] stated that the corrosion resistance of UFG Cu was significantly reduced in comparison with the CG sample. Therefore, it is extremely valuable to investigate the SCC behavior of UFG Cu alloy produced by ECAP. The aim of the current research was to clarify the influence the mechanism of grain refinement has on the SCC behavior of $\mathrm{Cu}-\mathrm{Cr}-\mathrm{Zr}$ alloy in $\mathrm{NaNO}_{2}$ solutions and air. The as-cast $\mathrm{Cu}-\mathrm{Cr}-\mathrm{Zr}$ alloy with the CG microstructure was also studied as a reference, which opens a new window for the design of UFG $\mathrm{Cu}$ alloys with superior SCC resistance.

\section{Materials and Methods}

The actual chemical composition of the cast $\mathrm{Cu}-\mathrm{Cr}-\mathrm{Zr}$ alloy is shown in Table 1 . The alloys were fabricated via hot extrusion at a temperature of $880^{\circ} \mathrm{C}$, and then subjected to solution treatment at a temperature of $980^{\circ} \mathrm{C}$ for $40 \mathrm{~min}$ followed by quenching in water. Part of the quenched rods were subjected to ECAP processing at room temperature for eight passes via route $\mathrm{Bc}\left(90^{\circ} \mathrm{C}\right.$ anticlockwise rotation of the samples after each ECAP pass). Then, all samples were aged at $450{ }^{\circ} \mathrm{C}$ for $3 \mathrm{~h}$. The aging treatment was carried out in flowing $\mathrm{Ar}$ atmosphere in an electric resistance furnace with an accurate temperature control of $\pm 5^{\circ} \mathrm{C}$. The microstructures of the samples were observed by optical microscopy (OM, OLYMPUS, Tokyo, Japan) and transmission electron microscopy (TEM, JEM-200CX, Tokyo, Japan) operating at $200 \mathrm{kV}$. The residual stress of specimens was measured by X-ray diffraction (XRD, Bruker, Karlsruhe, Germany). The tensional residual stress of the UFG specimen was larger than that of the CG specimen and their difference was $7 \mathrm{MPa}$, as shown in Table 2.

Table 1. Actual chemical composition of the $\mathrm{Cu}-\mathrm{Cr}-\mathrm{Zr}$ alloy.

\begin{tabular}{cccccccc}
\hline \multirow{2}{*}{ Alloy } & \multicolumn{9}{c}{ Chemical Composition (wt.\%) } & & \\
& $\mathbf{C r}$ & $\mathbf{Z r}$ & $\mathbf{F e}$ & $\mathbf{N i}$ & $\mathbf{P b}$ & $\mathbf{Z n}$ & $\mathbf{C u}$ \\
\hline $\mathrm{Cu}-\mathrm{Cr}-\mathrm{Zr}$ & $0.83-0.84$ & $0.15-0.20$ & $\leq 0.03$ & $\leq 0.02$ & $\leq 0.002$ & $\leq 0.003$ & Bal. \\
\hline
\end{tabular}

Table 2. Residual stress of the Cu-Cr-Zr alloy after aging. CG: coarse-grained; UFG: ultrafine-grained.

\begin{tabular}{ccc}
\hline Sample & CG & UFG \\
\hline Average residual stress $(\mathrm{MPa})$ & 35 & 42 \\
\hline
\end{tabular}

Slow strain rate technique (SSRT) tests were carried out to investigate the SCC behavior of $\mathrm{Cu}-\mathrm{Cr}-\mathrm{Zr}$ alloys under different conditions. SSRT tests were carried out on an Instron 1341 hydraulic servo fatigue machine (Instron 1341, London, UK) with a strain rate of $5 \times 10^{-4} \mathrm{~s}^{-1}$. A detailed schematic illustration is shown in Figure 1. Specimens of $6 \times 2.5 \mathrm{~mm}^{2}$ cross section and $6 \mathrm{~mm}$ gauge length were cut by spark erosion. The experimental medium was $1 \mathrm{M} \mathrm{NaNO}_{2}$ solution. The solution was continuously pumped during the experiment in order to ensure that the gauge length of the entire stretching process was always immersed in the corrosive fluid. After failure, fracture morphologies were observed by scanning electron microscopy (SEM, Gemini SEM 300, Karlsruhe, Germany), and the fracture corrosion products were measured by $\mathrm{XRD}$ using $\mathrm{Cu} \mathrm{K} \alpha$ radiation. 


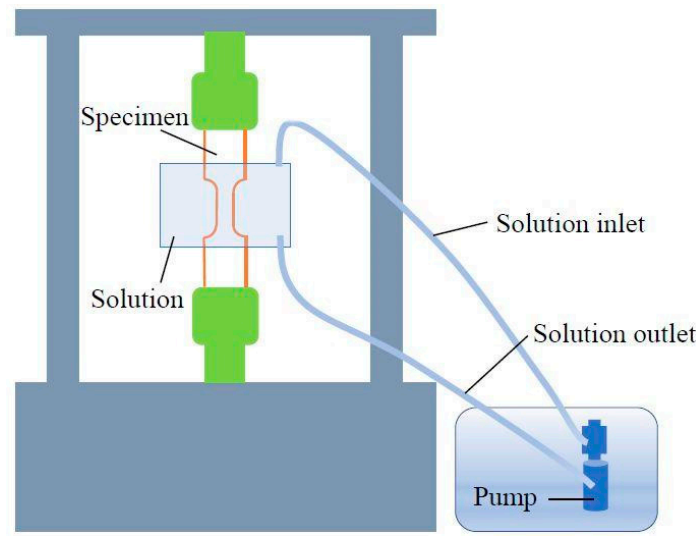

Figure 1. Schematic of the experimental set-up of the slow strain rate technique (SSRT) test.

\section{Results and Discussion}

\subsection{Microstructure}

Figure 2 shows the OM and TEM micrographs of the CG and UFG Cu-Cr-Zr alloys, respectively. From Figure 2a, it can be seen that the grain boundaries of CG samples were very clear and took on near full equiaxial grain morphology with an average grain size of about $50 \mu \mathrm{m}$. There were very few dislocations within the grains, which was manifested by a completely recrystallized microstructure. The aging treatment led to the precipitation of high-density $\mathrm{Cr}$ particles with a diameter of $10 \mathrm{~nm}$. Among them, a small part of $\mathrm{Cr}$ particles were concentrated within the grain (Figure 2b). ECAP processing caused significant grain refinement, and a large number of dislocations in the matrix can still be observed in Figure 2c. The average grain size of the UFG specimens were calculated as $\sim 200 \mathrm{~nm}$. After aging treatment, the dislocation density was remarkably reduced. In addition, the precipitation of Cr particles was less in comparison to CG alloys.
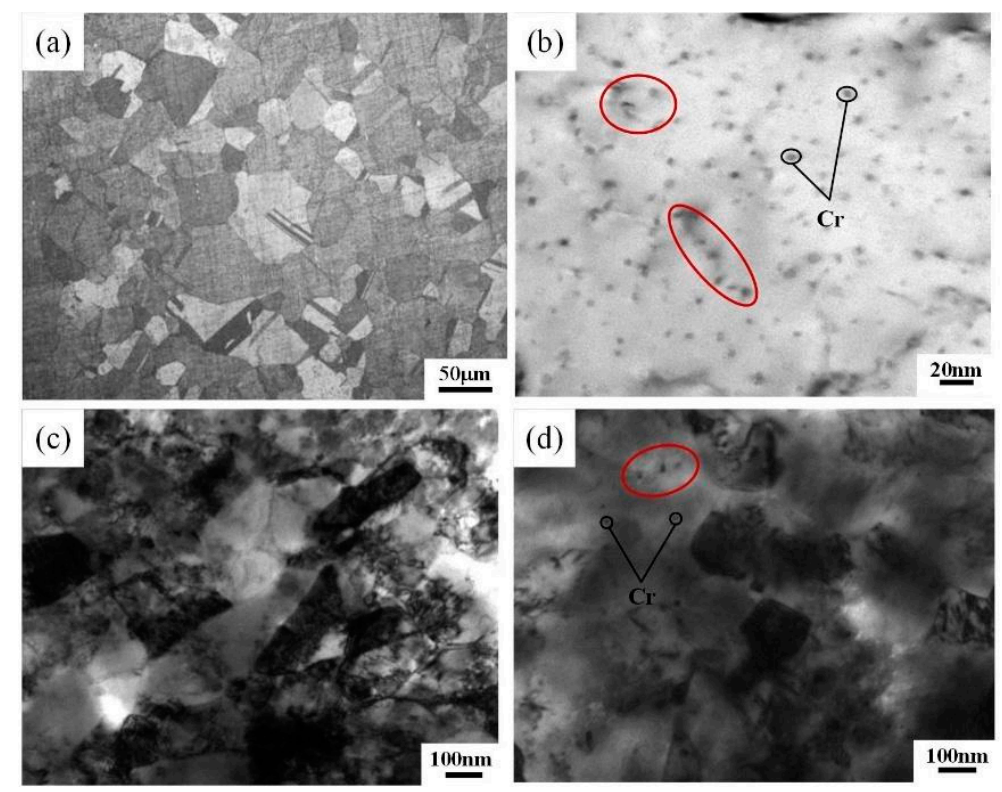

Figure 2. (a) Optical microscopy (OM) of the CG sample with solution at $980{ }^{\circ} \mathrm{C}$ for $40 \mathrm{~min}$; (b) transmission electron microscopy (TEM) images of the CG sample after aging at $450{ }^{\circ} \mathrm{C}$ for $3 \mathrm{~h}$; (c) TEM images of UFG sample with solution at $980^{\circ} \mathrm{C}$ for $40 \mathrm{~min}$; and (d) TEM images of UFG sample after aging at $450^{\circ} \mathrm{C}$ for $3 \mathrm{~h}$. 


\subsection{Stress Corrosion Behavior}

The ultimate tensile strength (UTS) and elongation values of the CG and UFG alloys $\left(\mathrm{NaNO}_{2}\right.$ solution and air) are displayed in Figure 3. The UFG alloys exhibited an ultra-high tensile yield strength as compared to the CG alloys, which was related to the intensive grain refinement effect derived from dynamic recrystallization behavior during the repeated ECAP process. The UTS of UFG Cu-Cr-Zr alloy in air and in the medium almost completely coincided. For the CG specimens, the UTS in the $\mathrm{NaNO}_{2}$ solution was lower than that in air, and the degradation in elongation was more pronounced, from $57.3 \%$ to $52.6 \%$. Thus, it becomes obvious that the resistance to SCC of the UFG Cu-Cr-Zr alloy was higher than that of the CG counterpart in $1 \mathrm{M} \mathrm{NaNO}_{2}$ solution. To quantify the SCC susceptibility of the samples tested under different conditions, the SCC susceptibility index $\left(I_{\delta}\right.$ and $\left.I_{\sigma}\right)$ was calculated by the decline in elongation and area reduction, which can be described by the following two equations:

$$
\begin{aligned}
& I_{\delta}=\left(1-\frac{\varepsilon_{\text {UTS }}^{S}}{\varepsilon_{U T S}^{A}}\right) \times 100 \%, \\
& I_{\sigma}=\left(1-\frac{\sigma_{U T S}^{S}}{\sigma_{U T S}^{A}}\right) \times 100 \%,
\end{aligned}
$$

wherein $\varepsilon_{U T S^{\prime}}^{A}, \sigma_{U T S^{\prime}}^{A}$ and $t_{f}^{A}$ represent the elongation, fracture strength, and fracture time in air, respectively. $\varepsilon_{U T S^{\prime}}^{S} \sigma_{U T S^{\prime}}^{S}$ and $t_{f}^{S}$ are the corresponding values in the $\mathrm{NaNO}_{2}$ solution, respectively. Table 3 summarizes the change and decrease in terms of strength and plasticity, respectively, for the comparison of their mechanical properties. $I_{\delta}$ and $I_{\sigma}$ were significantly decreased by ECAP. The analysis above indicates that to a certain extent, the SCC susceptibility of UFG Cu-Cr-Zr alloy was smaller than that for its CG counterpart.

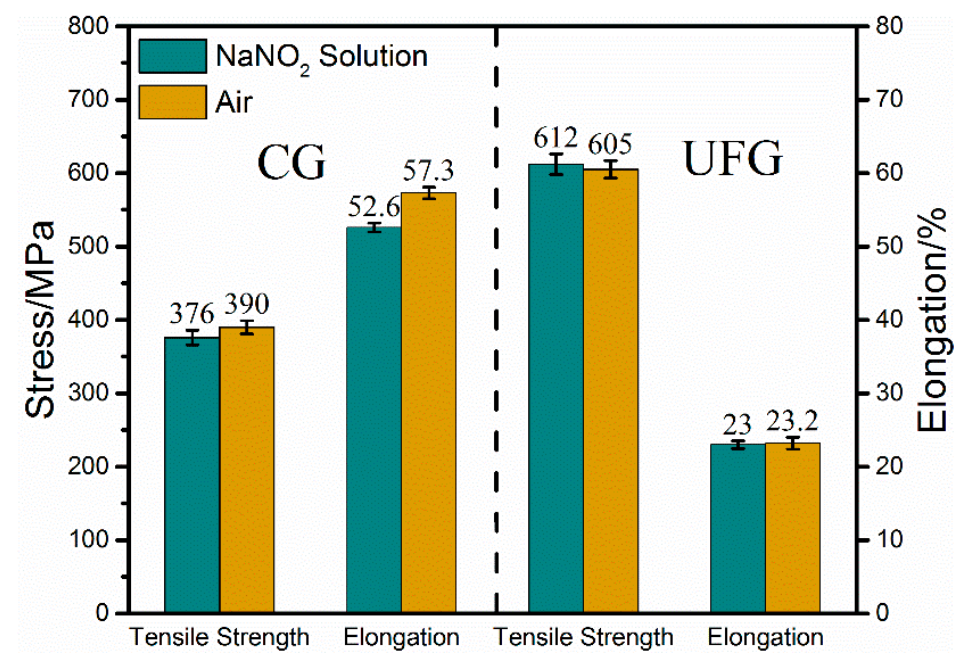

Figure 3. The average ultimate tensile strength (UTS) and elongation of CG and UFG alloys with $\mathrm{NaNO}_{2}$ solution and air.

\begin{tabular}{|c|c|c|c|c|c|c|c|}
\hline Parameter & Solution & $\sigma_{\text {UTS }}(\mathbf{M P a})$ & $(\%)$ & $\varepsilon_{U T S}(\%)$ & $I_{\delta}(\%)$ & $t_{f}(\mathrm{~h})$ & $\frac{t_{f}^{A}}{t_{f}^{S}}$ \\
\hline $\begin{array}{c}\mathrm{CG} \\
\mathrm{Cu}-\mathrm{Cr}-\mathrm{Zr}\end{array}$ & $\begin{array}{c}\mathrm{NaNO}_{2} \\
\text { In air }\end{array}$ & $\begin{array}{l}376 \\
390\end{array}$ & 3.6 & $\begin{array}{l}52.6 \\
57.3\end{array}$ & 8.4 & $\begin{array}{l}14 \\
16\end{array}$ & 1.14 \\
\hline $\begin{array}{c}\text { UFG } \\
\mathrm{Cu}-\mathrm{Cr}-\mathrm{Zr}\end{array}$ & $\begin{array}{c}\mathrm{NaNO}_{2} \\
\text { In air }\end{array}$ & $\begin{array}{l}612 \\
605\end{array}$ & -1.2 & $\begin{array}{c}23 \\
23.2\end{array}$ & 0.9 & $\begin{array}{l}6.38 \\
6.43\end{array}$ & 1.01 \\
\hline
\end{tabular}

Table 3. Stress corrosion cracking (SCC) results of $\mathrm{Cu}-\mathrm{Cr}-\mathrm{Zr}$ alloys in $1 \mathrm{M} \mathrm{NaNO}_{2}$ solution. 
Figure 4 shows the fracture morphologies tested in air and $\mathrm{NaNO}_{2}$ solution, respectively. The $\mathrm{CG}$ samples showed an obvious dissolution, microvoids, and minor cracks in $\mathrm{NaNO}_{2}$ solution compared to in air, and a stress corrosion zone was clearly visible (Figure 4c). On the contrary, the fracture surface of the UFG specimen was essentially the same in air as in solution, and the surface was flat without large corrosion ditches (Figure $4 \mathrm{e}, \mathrm{g}$ ). Therefore, the stress of SCC in the CG sample was much lower than that of $\sigma_{\text {UTS }}$, while the UFG sample appeared to be immune to SCC until it was close to the relatively high stress of $\sigma_{U T S}$. The characteristics of CG and UFG specimens fracture surface failure in $\mathrm{NaNO}_{2}$ solution were similar to those observed by Yamasaki [14]. The stress corrosion of CG samples in $\mathrm{NaNO}_{2}$ solution was generally a transgranular fracture mode. For both types of specimens, fracture dimples were significantly different. The dimples of CG samples were large and the crack aggregation and diffusion ability was strong (Figure $4 \mathrm{~d}$ ), suggesting that when in solution it underwent enormous losses in ductility and strength, therefore indicating a very high SCC susceptibility compared to the UFG alloys. It also showed a transgranular dimple fracture. A typical dimpled structure can be observed in Figure 4f,h. When UFG samples were tested in air and in solution, fine and dense dimples were observed in the fracture. They were corroded uniformly when the aggressive ions attacked their surfaces. Intergranular SCC occurred in UFG Cu-Cr-Zr alloys, which was attributed to its high grain boundary volume fraction, and the grain boundary weakening due to chemical corrosion and stress corrosion along grain boundaries [16].

\subsection{SCC Mechanism}

The enhanced SCC resistance of the ECAP alloy was mainly related to the UFG structure and its high volume fraction of grain boundaries because the tensional residual stress of UFG alloys was greater than that of CG alloys. It is necessary to analyze the change in the microstructure from plastic deformation and the degree of localization of corrosion damage. Among them, grain size is an important factor that affects the corrosion resistance of metals. After plastic deformation, the increase of volume fraction of grain boundary reduces the local corrosion rate and the chance of pitting. Grain refinement has been demonstrated to improve the corrosion resistance [18,19]. The 409 stainless steel enables surface nanocrystallization by surface mechanical attrition treatment, which promotes passivation film formation and improves corrosion resistance [20]. ECAP-produced UFG Ti exhibited an improved corrosion resistance in artificial seawater, compared with CG Ti [21]. It was found in a previous study [22] that compared with CG materials, a large number of grain boundaries in UFG alloys enhance the passivation kinetics, and the mismatch between the passive film and metal matrix is reduced. In addition, grain refinement can improve the resistance to crack growth. ECAP processing can bring a homogenous structure, which is conducive to the occurrence of even corrosion. The consistency between the grain interiors and the grain boundary will be improved, which effectively restricts the local corrosion behavior. It has been reported $[19,23]$ that the grain interiors after ECAP had higher energy storage and promoted the passivation-repassivation process, thereby improving the corrosion resistance of the grains. Therefore, a large stress corrosion zone area was observed in the CG fracture (Figure 4c). In a neutral or alkaline environment, the corrosion of $\mathrm{Cu}-\mathrm{Cr}-\mathrm{Zr}$ alloys are listed as follows $[13,17,24]$ :

Anode reaction:

$$
\begin{aligned}
\mathrm{Cu} & \rightarrow \mathrm{Cu}^{+}+\mathrm{e}^{-}, \\
\mathrm{Cu} & \rightarrow \mathrm{Cu}^{2+}+2 \mathrm{e}^{2-} \\
\mathrm{Cr} & \rightarrow \mathrm{Cr}^{3+}+3 \mathrm{e}^{-} \\
\mathrm{Zr} & \rightarrow \mathrm{Zr}^{4+}+4 \mathrm{e}^{-}
\end{aligned}
$$

Cathodic reaction:

$$
\mathrm{O}_{2}+2 \mathrm{H}_{2} \mathrm{O}+4 \mathrm{e}^{-} \rightarrow 4 \mathrm{OH}^{-}
$$



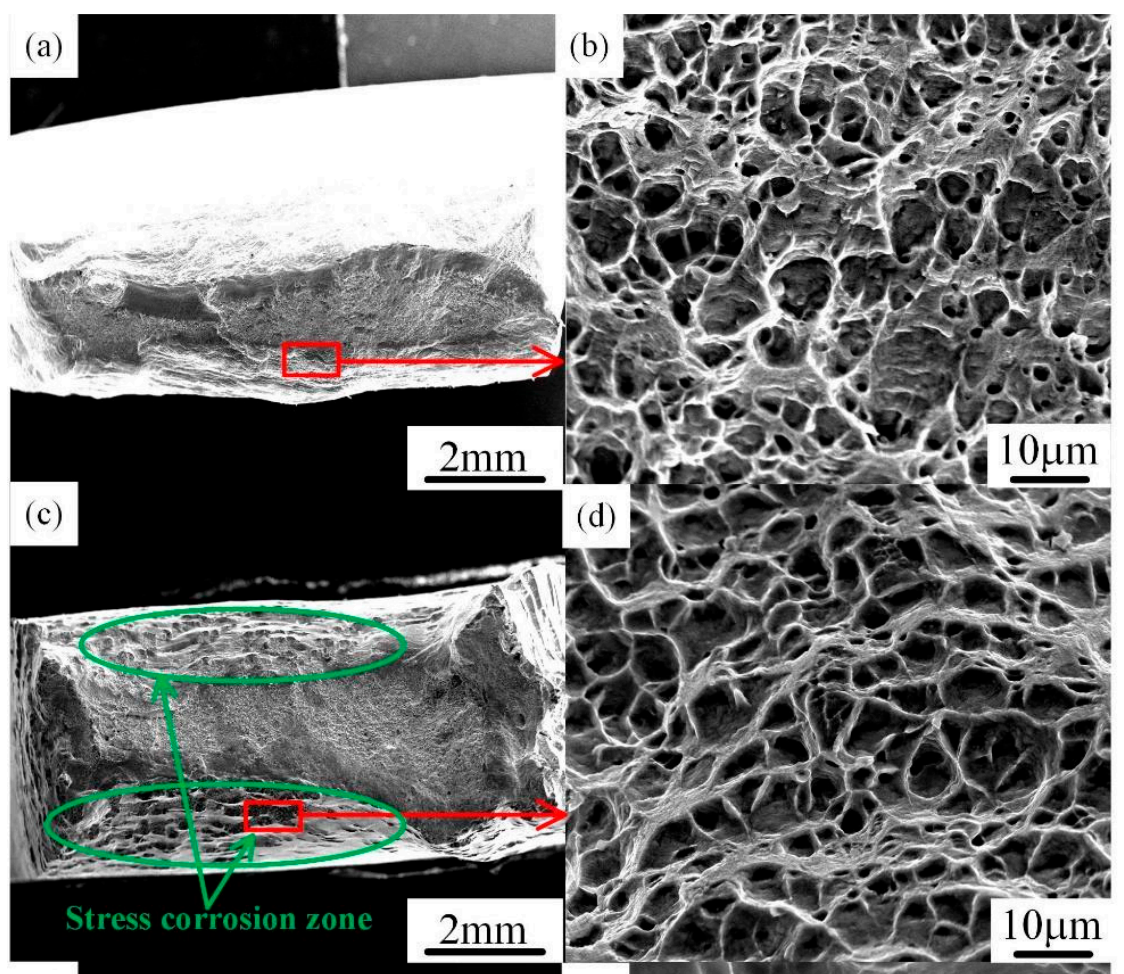

(e)
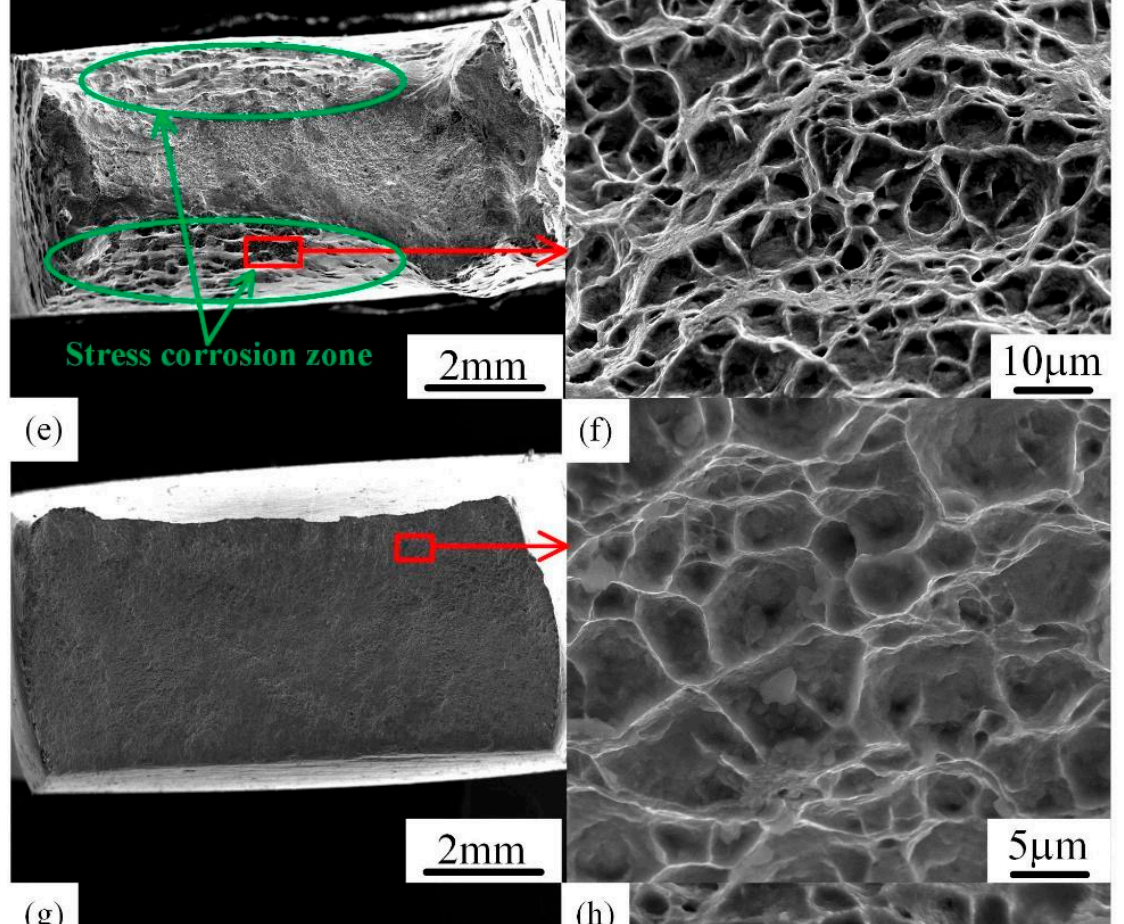

(f)

(g)
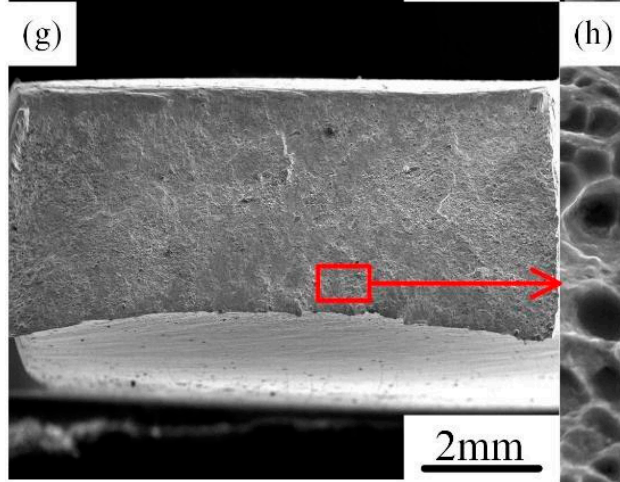

(h)

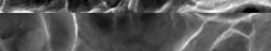

sace

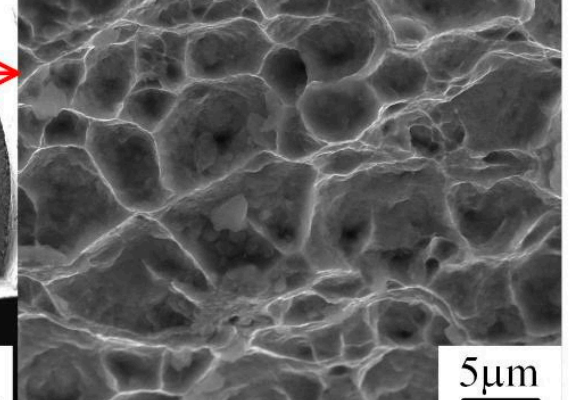

(9)

4. (a) Low- and (b) high-magnification scanning electron microscopy (SEM) fractographs of CG sample in air. (c) Low- and (d) high-magnification SEM fractographs of CG sample in $\mathrm{NaNO}_{2}$ solution. (e) Low- and (f) high-magnification SEM fractographs of UFG sample in air. (g) Low- and (h) high-magnification SEM fractographs of UFG sample in $\mathrm{NaNO}_{2}$ solution.

Figure 5 shows the $\mathrm{X}$-ray diffraction patterns of the fracture surface. The XRD analysis indicated the presence of diffraction peaks of $\mathrm{Cu}_{2} \mathrm{O}$ and $\mathrm{ZrO}_{2}$ on the surface of the samples. At the same time, $\mathrm{Cu}_{2}(\mathrm{OH})_{2}\left(\mathrm{NO}_{2}\right)_{2}$ also appeared on the surface of the substrate. The formation of passivation film in 
$\mathrm{NaNO}_{2}$ solution on the surface of the investigated alloys may involve the following electrochemical steps [13]:

$$
\begin{gathered}
\mathrm{Zr}^{4+}+\mathrm{O}_{2} \rightarrow \mathrm{ZrO}_{2} \\
4 \mathrm{Cu}+\mathrm{O}_{2} \rightarrow 2 \mathrm{Cu}_{2} \mathrm{O} \\
\mathrm{Cu}^{2+}+\mathrm{NO}_{2}^{-} \rightarrow \mathrm{CuNO}_{2}^{+} \\
\mathrm{Cu}^{2+}+2 \mathrm{NO}_{2}^{-} \rightarrow \mathrm{Cu}\left(\mathrm{NO}_{2}\right)_{2} \\
\mathrm{Cu}^{2+}+2 \mathrm{NO}_{2}^{-}+2 \mathrm{OH}^{-} \rightarrow \mathrm{Cu}_{2}(\mathrm{OH})_{2}\left(\mathrm{NO}_{2}\right)_{2}
\end{gathered}
$$

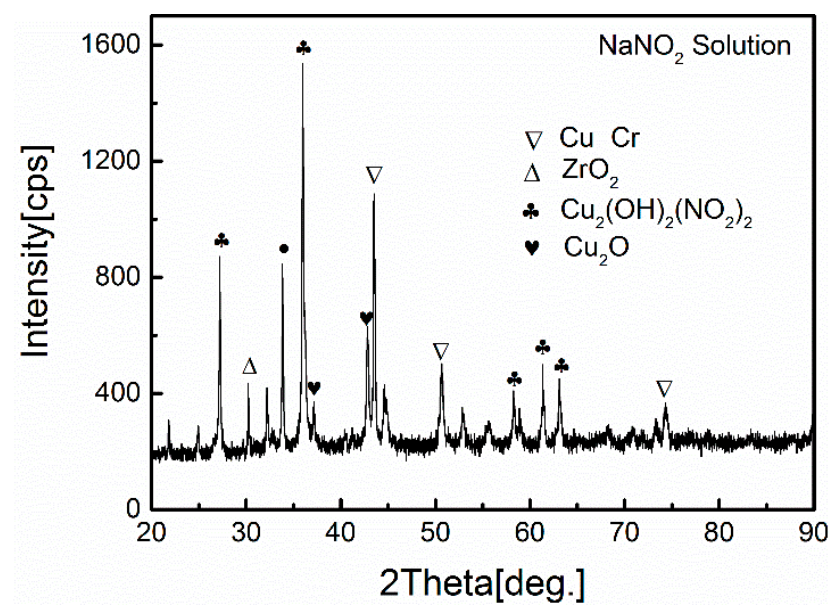

Figure 5. X-ray diffraction (XRD) analysis map of corrosion product film in $\mathrm{NaNO}_{2}$ solution.

The metal surface is contacted with a $\mathrm{NaNO}_{2}$ solution in which copper dissolves the anode, and partially dissolved copper will exist as a moderately stable complex. The UFG samples could not form a new sufficiently stable protective film on the original $\mathrm{Cu}_{2} \mathrm{O}$ and $\mathrm{CuO}$ protective film in the $\mathrm{NaNO}_{2}$ solution. The bare metal surface could catalyze the formation of $\mathrm{NH}_{4}{ }^{+}$by $\mathrm{NO}_{2}{ }^{-}$ions at the crack tip, while the $\mathrm{NH}_{4}{ }^{+}$ion can form $\mathrm{Cu}\left(\mathrm{NH}_{3}\right)_{2}{ }^{+}$ions complex with $\mathrm{Cu}^{+}$ions, which promotes the dissolution of $\mathrm{Cu}$ and leads to the occurrence of stress corrosion cracking behavior [25].

According to the microstructure analysis, the precipitate phase of the UFG Cu-Cr-Zr alloy was a pure $\mathrm{Cr}$ phase in the form of bcc and $\mathrm{Cu}_{x} \mathrm{Zr}_{\mathrm{y}}$ [26,27]. After aging treatment, $\mathrm{Cr}$ and $\mathrm{Zr}$ improved the strength of the material through solid solution strengthening, namely high-temperature solid solution and low-temperature precipitation. It is also important that the distribution of $\mathrm{Cr}$ in the matrix affected the corrosion of UFG alloys. After the aging, the Cr particles precipitated by CG alloys were partially accumulated on the grain interiors (Figure $2 b$ ), resulting in a heterogeneous microstructure, which affected the formation of the passivation film. On the contrary, the uniform distribution of Cr in UFG alloy greatly improved the corrosion. The uniform distribution of $\mathrm{Cr}$ brought about the decrease of the electrochemical potential difference between $\mathrm{Cu}$ matrix and $\mathrm{Cr}$ particles.

To clarify the effect of the two samples' corrosion processes in the $\mathrm{NaNO}_{2}$ solution, the overall schematic illustration is shown in Figure 6. Generally, as the experiment progressed, the area around the sample suffered from localized corrosion, and the localized corrosion areas could further expand [16]. Figure 6a shows transgranular corrosion and transgranular SCC, and Figure 6b shows intergranular corrosion and intergranular SCC. For the CG samples, the severity of localized corrosion and the number of microvoids were greater than in the UFG samples tested in $\mathrm{NaNO}_{2}$ solution. The surface film of the CG samples was continuously destroyed, and severe stress corrosion occurred in the fracture (Figure 4c). An obviously preferential grain boundary degradation and selective corrosion of some grain interiors was observed in CG Cu-Cr-Zr alloys. At the same time, the uneven distribution of $\mathrm{Cr}$ particles and the increase of grain boundary defects made the chemical activity of the surface layer 
inconsistent, which prevented the growth of the passivation film at these active sites (Figure 6a). This caused the passivation film to grow irregularly, which contained more ion vacancies. The passivation film was also more susceptible to damage, and the passivation ability was weakened. On the contrary, the corrosion area of the UFG alloy was much smaller compared with that of the CG alloy, due to the increased volume fraction of grain boundaries. The SEM micrographs (Figure 4f,h) illustrate the intergranular SCC. Grain boundaries can act as a barrier to the development of corrosion [23]. The UFG alloys greatly hindered further corrosion of the solution due to the high grain boundary ratio. Finally, this caused the significant SCC difference between UFG and ordinary CG Cu-Cr-Zr alloys.

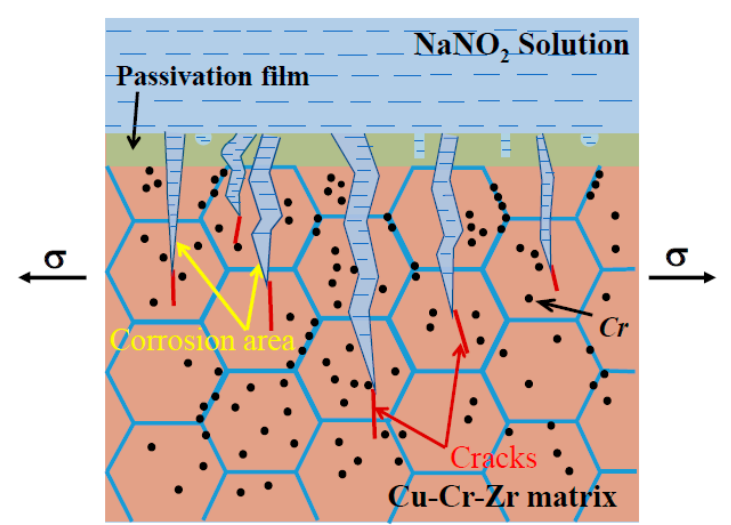

(a)

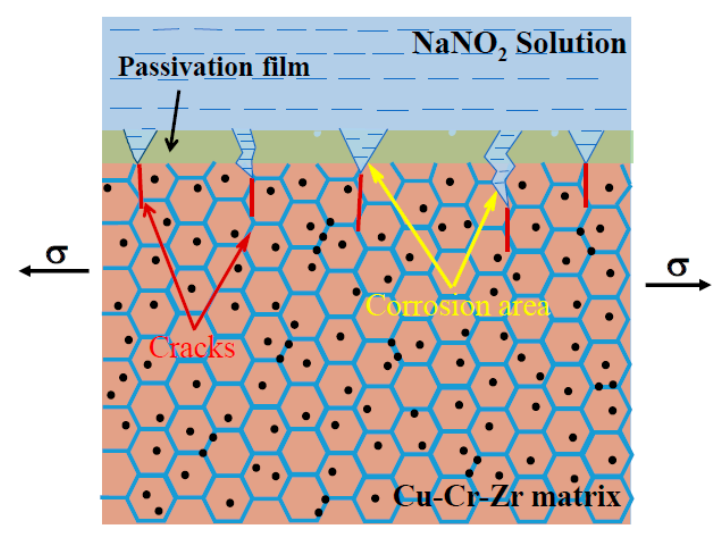

(b)

Figure 6. Corrosion mechanism diagram in $\mathrm{NaNO}_{2}$ solution: (a) $\mathrm{CG} \mathrm{Cu}-\mathrm{Cr}-\mathrm{Zr}$ alloy and (b) UFG $\mathrm{Cu}-\mathrm{Cr}-\mathrm{Zr}$ alloy.

\section{Conclusions}

The sensitivity of CG and UFG Cu-Cr-Zr alloys to SCC in air and $1 \mathrm{M} \mathrm{NaNO}_{2}$ solution was studied by SSRT. The results show that the UFG sample represented an ultra-low SCC sensitivity under the corrosion condition of $1 \mathrm{M} \mathrm{NaNO}_{2}$ solution. The tensile curves in air and medium were almost identical, indicating that the corrosive medium and the small amount of stress corrosion cracking had no significant effect on the mechanical properties of the UFG samples. In the $\mathrm{NaNO}_{2}$ solution, only the CG sample was subjected to stress corrosion. The CG sample fracture showed considerable dissolution, microvoids, and minor cracks, while the surface of the UFG sample was smooth. The ECAP processing caused an increase in the volume fraction of grain boundaries, which blocked the further occurrence of local corrosion behavior. On the other hand, the $\mathrm{Cr}$ particles were uniformly distributed in the UFG alloys, which reduced the electrochemical potential difference between $\mathrm{Cu}$ matrix and $\mathrm{Cr}$ particles, thereby improving the quality of the passivation film. Therefore, the ECAP process is an effective approach for the design of Cu-Cr-Zr alloys with superior SCC resistance in the future.

Author Contributions: Conceptualization, Q.W.; Data curation, D.L.; Formal analysis, Q.W. and L.T.; Investigation, Y.Z.; Validation, W.W.; Writing—original draft, D.L.; Writing—review and editing, H.Z. and R.F.

Funding: This research was funded by the National Natural Science Foundation of China (grant number 51771178) and the Shaanxi Provincial Department of Education 2019 Annual Service for Local Science Research Project (grant number 19JC025).

Acknowledgments: The authors are grateful to the other members of their research team for their help in the experimental process.

Conflicts of Interest: The authors declare no conflict of interest.

\section{References}

1. Mishnev, R.; Shakhova, I.; Belyakov, A.; Kaibyshev, R. Deformation microstructures, strengthening mechanisms, and electrical conductivity in a $\mathrm{Cu}-\mathrm{Cr}-\mathrm{Zr}$ alloy. Mater. Sci. Eng. A 2015, 629, 29-40. [CrossRef] 
2. Peng, L.J.; Xie, H.F.; Huang, G.J.; Xu, G.L.; Yin, X.Q.; Feng, X.; Mi, X.J.; Yang, Z. The phase transformation and strengthening of a Cu-0.71wt\% Cr alloy. J. Alloys Compd. 2017, 708, 1096-1102. [CrossRef]

3. Xiao, B.C.; Feng, J.; Jing, Y.J.; Pian, X.; Meng, M.T.; Zhong, Q.T. Precipitation, Recrystallization, and Evolution of Annealing Twins in a Cu-Cr-Zr Alloy. Metals 2018, 8, 227.

4. Abib, K.; Balanos, J.A.M.; Alili, B.; Bradai, D. On the microstructure and texture of Cu-Cr-Zr alloy after severe plastic deformation by ECAP. Mater. Charact. 2016, 112, 252-258. [CrossRef]

5. Xia, K.W.; Wei, W.; Wang, F.; Du, Q.B.; Alexandrov, I.V.; Hu, J. Microstructure, mechanical properties and electrical conductivity of industrial $\mathrm{Cu}-0.5 \% \mathrm{Cr}$ alloy processed by severe plastic deformation. Mater. Sci. Eng. A 2011, 528, 1478-1484.

6. Wu, S.H.; Zhang, P.; Shao, D.; Cheng, P.M.; Kuang, J.; Wu, K.; Zhang, J.Y.; Liu, G.; Sun, J. Grain size-dependent Sc microalloying effect on the yield strength-pitting corrosion correlation in Al-Cu alloys. Mater. Sci. Eng. A 2018, 721, 200-214. [CrossRef]

7. Guo, M.X.; Du, J.Q.; Zheng, C.H.; Zhang, J.S.; Zhuang, L.Z. Influence of Zn contents on precipitation and corrosion of Al-Mg-Si-Cu-Zn alloys for automotive applications. Mater. Sci. Eng. A 2019, 778, 256-270. [CrossRef]

8. Huang, A.H.; Wang, Y.F.; Wang, M.S.; Song, L.Y.; Li, Y.S.; Gao, L.; Huang, C.X.; Zhu, Y.T. Optimizing the strength, ductility and electrical conductivity of a $\mathrm{Cu}-\mathrm{Cr}-\mathrm{Zr}$ alloy by rotary swaging and aging treatment. Mater. Sci. Eng. A 2019, 746, 211-216. [CrossRef]

9. Qiu, Y.X.; Ai, B.M.; Jing, H.J.; Zhao, J.C.; Dan, S.; Yu, C.Y.; Huan, L. Stress Corrosion Cracking Behavior of Fine-Grained AZ61 Magnesium Alloys Processed by Equal-Channel Angular Pressing. Metals 2017, 9, 343.

10. Purcek, G.; Yanar, H.; Demirtas, M.; Alemdag, Y.; Shangina, D.V.; Dobatkin, S.V. Optimization of strength, ductility and electrical conductivity of $\mathrm{Cu}-\mathrm{Cr}-\mathrm{Zr}$ alloy by combining multi-route ECAP and aging. Mater. Sci. Eng. A 2016, 649, 114-122. [CrossRef]

11. Pan, Z.Y.; Chen, J.B.; Li, J.F. Microstructure and properties of rare earth-containing $\mathrm{Cu}-\mathrm{Cr}-\mathrm{Zr}$ alloy. Trans. Nonferr. Met. Soc. China 2015, 25, 1206-1214. [CrossRef]

12. Shangina, D.V.; Bochvar, N.R.; Morozova, A.I.; Belyakov, A.N.; Kaibyshev, R.O.; Dobatkin, S.V. Effect of chromium and zirconium content on structure, strength and electrical conductivity of $\mathrm{Cu}-\mathrm{Cr}$ - $\mathrm{Zr}$ alloys after high pressure torsion. Mater. Lett. 2017, 199, 46-49. [CrossRef]

13. Rebak, R.B.; Carranza, R.M.; Galvele, J.R. Stress Corrosion Cracking Mechanism of $\alpha-B_{r a s s}$ in $\mathrm{NaNO}_{2}$ Solutions. Corros. Sci. 1988, 28, 1089-1106. [CrossRef]

14. Yamasaki, T.; Miyamoto, H.; Mimaki, T.; Vinogradov, A.; Hashimoto, S. Stress corrosion cracking susceptibility of ultra-fine grain copper produced by equal-channel angular pressing. Mater. Sci. Eng. A 2001, 318, 122-128. [CrossRef]

15. Wang, L.C.; Li, D.Y. Mechanical, electrochemical and tribological properties of nanocrystalline surface of brass produced by sandblasting and annealing. Surf. Coat. Technol. 2003, 167, 188-196. [CrossRef]

16. Sadawy, M.M.; Ghanem, M. Grain refinement of bronze alloy by equal-channel angular pressing (ECAP) and its effect on corrosion behavior. Def. Technol. 2016, 12, 316-323. [CrossRef]

17. Vinogradov, A.; Mimaki, T.; Hashimoto, S.; Valiev, R. On the corrosion behaviour of ultra-fine grain copper. Scr. Mater. 1999, 41, 319-326. [CrossRef]

18. Miyamoto, H.; Harada, K.; Mimaki, T.; Vinogradov, A.; Hashimoto, S. Corrosion of ultra-fine grained copper fabricated by equal-channel angular pressing. Corros. Sci. 2008, 50, 1215-1220. [CrossRef]

19. Jang, Y.H.; Kim, S.S.; Han, S.Z.; Lim, C.Y.; Kim, C.J. Corrosion and stress corrosion cracking behavior of equal channel angular pressed oxygen-free copper in 3.5\% NaCl solution. J. Mater. Sci. 2006, 41, 4293-4297. [CrossRef]

20. Balusamy, T.; Kumar, S.; Sankara Narayanan, T.S.N. Effect of surface nanocrystallization on the corrosion behaviour of AISI 409 stainless steel. Corros. Sci. 2010, 52, 3826-3834. [CrossRef]

21. Gu, Y.X.; Ma, A.B.; Jiang, J.H.; Li, H.Y.; Song, D.; Wu, H.R.; Yuan, Y.C. Simultaneously improving mechanical properties and corrosion resistance of pure Ti by continuous ECAP plus short-duration annealing. Mater. Charact. 2018, 138, 38-47. [CrossRef]

22. Balyanov, A.; Kutnyakova, J.; Amirkhanova, N.A.; Stolyarov, V.V.; Valiev, R.Z.; Liao, X.Z.; Zhao, Y.H.; Jiang, Y.B.; Xu, H.F.; Lowe, T.C.; et al. Corrosion resistance of ultra fine-grained Ti. Scr. Mater. 2004, 51, 225-229. [CrossRef] 
23. Brunner, J.G.; May, J.; Höppel, H.W.; Göken, M.; Virtanen, S. Localized corrosion of ultrafine-grained Al-Mg model alloys. Electrochim. Acta 2010, 55, 1966-1970. [CrossRef]

24. Zhou, P.; Ogle, K. The corrosion of copper and copper alloys. In Encyclopedia of Interfacial Chemistry; Elsevier Inc.: Amsterdam, The Netherlands, 2018; pp. 478-489.

25. Mimaki, T.; Nakazawa, Y.; Hashimoto, S.; Miura, S. Stress corrosion cracking of copper bicrystals with $\langle 110\rangle$ -Tilt $\sum 3, \sum 9$, and $\sum 11$ coincident site lattice boundaries. Metall. Trans. A 1990, 21, 2355-2361. [CrossRef]

26. Anna, M.; Elijah, B.; Vladimir, B.; Sergey, Z.; Andrey, B.; Rustam, K. Grain refinement kinetics in a low alloyed $\mathrm{Cu}-\mathrm{Cr}-\mathrm{Zr}$ alloy subjected to large strain deformation. Materials 2017, 10, 1394.

27. Edwards, D.J.; Singh, B.N.; Tähtinen, S. Effect of heat treatments on precipitate microstructure and mechanical properties of a CuCrZr alloy. J. Nucl. Mater. 2007, 367, 904-909. [CrossRef]

(C) 2019 by the authors. Licensee MDPI, Basel, Switzerland. This article is an open access article distributed under the terms and conditions of the Creative Commons Attribution (CC BY) license (http://creativecommons.org/licenses/by/4.0/). 